\title{
THE USE OF UAV SYSTEMS FOR MAPPING OF BUILT-UP AREA
}

\author{
B. Ruzgiene ${ }^{\mathrm{a}}$, C. Aksamitauskas ${ }^{\mathrm{b}}$
}

\author{
${ }^{\mathrm{a}, \mathrm{b}}$ Dept of Geodesy and Cadastre, Vilnius Gediminas Technical University, Sauletekio al.11, LT-10223, Lithuania \\ Birute.Ruzgiene@vgtu.lt, ceslovas.aksamitauskas@vgtu.lt
}

KEY WORDS: Digital Photogrammetry, UAV, Accuracy Investigation, Mapping Techniques

\begin{abstract}
:
The Low-cost Unmanned Aerial Vehicle (UAV) has been used as a platform for photogrammetric data acquisition. Two techniques were accepted for mapping. One is remotely-piloted aircraft with mounted digital camera Sony NEX-5 for low altitude photogrammetry. The flying height was about $30 \mathrm{~m}$. Another is close range photogrammetry taking images from building - geometric situation similar to aerial case (vertical images). The Trimble R6 GPS has been used for determination of ground control points coordinates exploited in exterior orientation procedures. DTM's creation via image matching and area mapping was performed by software LISA designed at University of Düsseldorf. Comparison analysis of applied two techniques efficiency and application possibilities has been carried out. The accuracy assessment is given. The residuals in $\mathrm{x}$ and $\mathrm{y}$ at every point and standard deviation in exterior orientation procedure of images from UAV platform is about half of pixel size referring to the image, i.e. $0,14 \mathrm{~mm}$. Experimental accuracy investigation regarding UAV and GPS data shows that maximum absolute planimetric displacement is 0,25$0,30 \mathrm{~m}$. Such data fulfils the accuracy requirements for large-scale urban area mapping.
\end{abstract}

\section{INTRODUCTION}

The application of digital photogrammetry for processing of images taken using platform named Unmanned Aerial Vehicles (UAV) with integrated sensor is rapidly growing. There arise new modern terminologies - UAV Photogrammetry, UAV Images. Definition of unmanned aerial vehicles might be confused because of unmanned meaning speculation. UAV is manned platform, because of handling remotely controlled equipment, but without a pilot sitting in the platform. Maybe definition - Remotely Operated Aerial Vehicles (ROAV) would be more acceptable.

Main features of UAV Photogrammetry are considered with respect on costs (low-cost), flying altitude (low-high), capability of image acquisition in real-time that's quality depends on sensors features, flight performance (e.g., flying speed 50-60 $\mathrm{km} / \mathrm{h}$ ), influence of atmospheric and environment conditions, wind influence, etc. Different types, classification, categorization of UAV's, applied for photogrammetric data acquisition are used (UAV Systems-Unmanned, 2013). UAV Photogrammetry data acquisition is possible in manual, semi-automated and automated flight mode.

Comparing the usage of UAVs and manned aircraft, UAV can be used in mapping of high-risk situations (e.g., disaster areas, mountains and volcanic zones, flood, earthquake and various accidents regions, etc.), without imminent danger to life of pilot. With the UAV system, due to its small size, can be taken photography very close to an object of very small space (territories that's shielded by trees or water bodies, narrow city streets, etc.). The cheap UAV vehicles are light, because of that there can be integrated ease (amateur) cameras, so the image resolution and quality may not always meet the needs of the user (Eisenbeiss, 2009).
UAV broad application possibilities for appropriate mapping needs (e.g., for inventory of electrical lines, etc.) depends on price of UAV system (variable, could be up to 30000 Euro).

The interest of UAV great potential for digital photogrammetry application is rising in many countries, as well as in Lithuania. Up-to-now there main fields of UAV application are the acquisition of cadastral area overlook images or for publicity needs.

Paper demonstrates results of investigation of images quality from UAV, flying over built up area, comparing with Close Range Photogrammetry images as well.

\section{TECHNOLOGICAL FEATURES}

After capturing the images, using different platforms and sensors, main photogrammetric procedures are: aerial triangulation, exterior orientation, creation of surface models, orthophoto generation, vector data collection for GIS or cartographic needs (Luhmann, 2006; Ruzgienè, 2008; Khosravani, 2010; Nilsson, 2009). Establishing the relation between image and object coordinates, nowadays the ground control point's coordinates are measured using GPS.

The images orientation: interior - camera parameters definition, exterior - for each image measuring ground control points, model definition (reconstruction of spatial geometry from two images, calculation using well known collinearity equations).

Creating DTMs via image matching, can be applied different methods, there is used area-based matching (ABM) approach that leads to good stereo pair correlation results. Area-based image matching compares the grey scale values of patches of two or more images and tries to find conjugate image 
locations based on similarity in those grey scale value patterns (Manual, 2004).

The area-based matching parameters are specified as the following: pixel size for DTMs (z-range) - for flat terrain is not necessary to match points for the high resolution, however, because of images oblique z-range selected smaller (not less than $0.2 \mathrm{~m})$; minimum correlation coefficient $(0.7-0.8)$ required for a pair of conjugate points to be considered as correspondence; correlation window size used to examine a small defined area, looking for matches to a topographic feature (the smallest window size is $5 \times 5$ square pixels, use a larger, e.g., $11 \times 11$ or $17 \times 17$ square pixels for higher resolution images in order to achieve more reliable matching results, but the process takes longer. The effect, when DTM pixels correlation is failed, is reduced decreasing the correlation coefficient threshold and decreasing the size of the correlation window.

The workflow diagram of experimental study for UAV Photogrammetry and Close Range imagery application is presented in Figure 1.

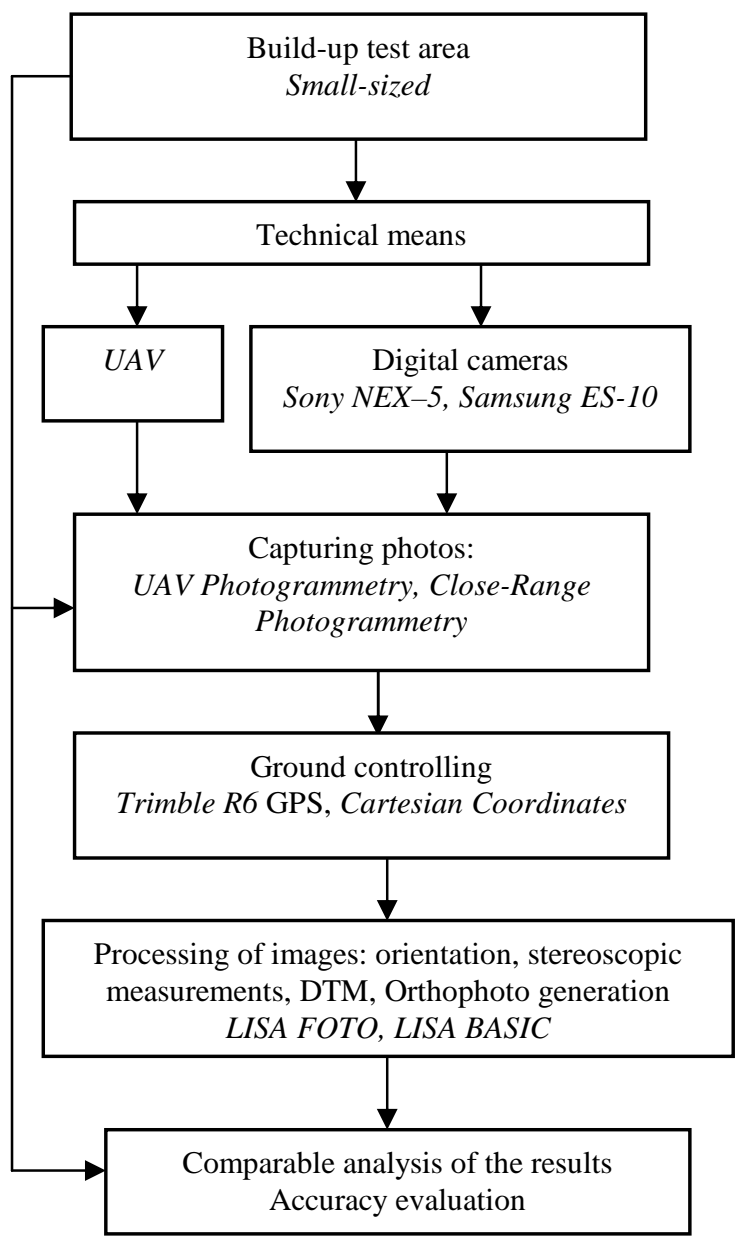

Figure 1. The workflow of experimental study

\section{EXPERIMENTAL PROCEDURES FOR DTM CREATION}

\subsection{Object, means and geodetic support}

The built-up area surrounding Vilnius Gediminas Technical University was selected as experimental test. For the first approach, the images were taken by self-constructed UAV remotely operated and with integrated digital camera Sony NEX-5 (see Fig. 2). Some characteristics of used digital camera: resolution - 14 mega-pixels $(4592 \times 3056)$, focal length $16 \mathrm{~mm}$, image's pixel size $72.6 \mu \mathrm{m}$, images storage formats JPG, RAW. UAV flying height was about $30 \mathrm{~m}$.

For the second approach, Close Range images have been taken from above (from building roof) with digital camera Samsung ES10 (resolution -8 mega-pixels, focal length $-6 \mathrm{~mm}$ ). The taking photography of test area was executed from about $23 \mathrm{~m}$ above ground surface, so images geometry became similar to aerial photography case, i.e. similar to geometry of vertical images.
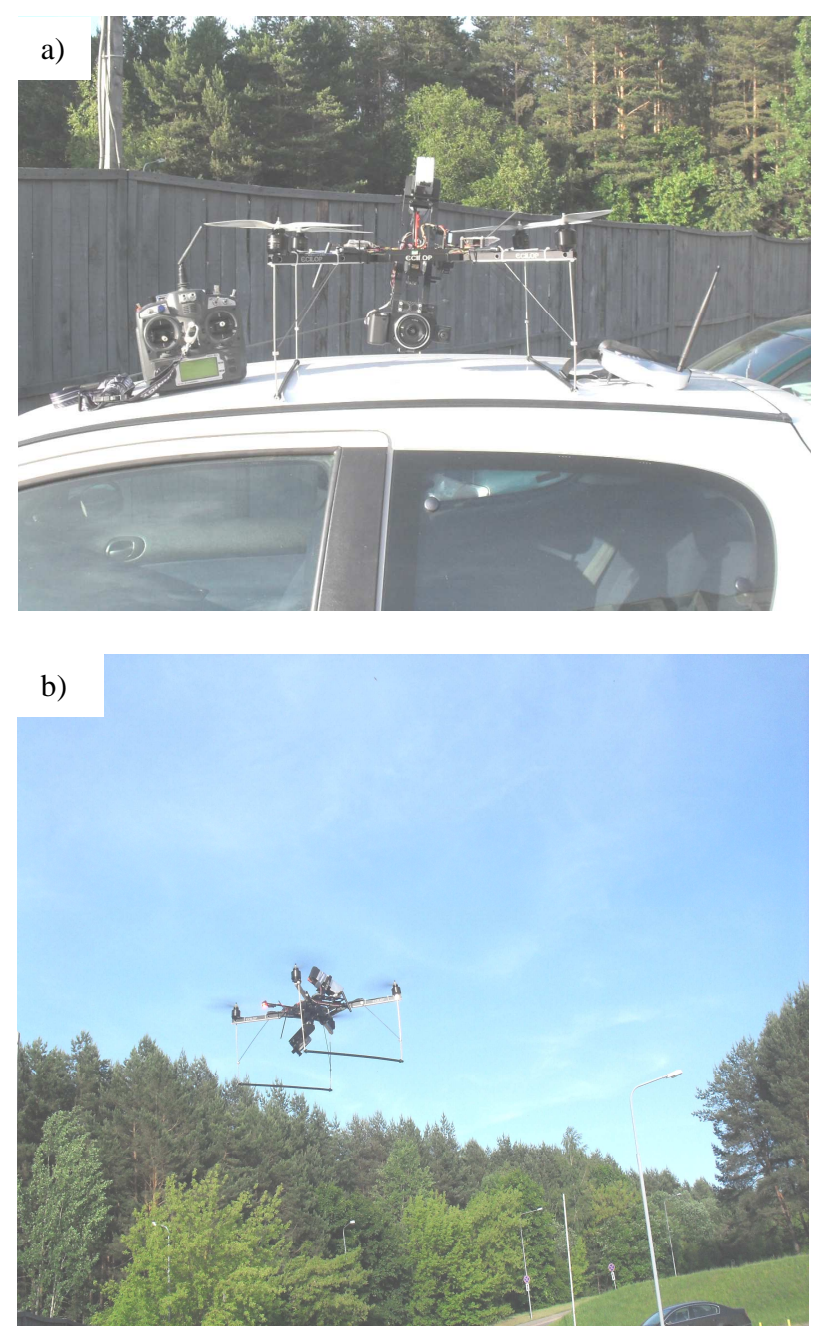

Figure 2. UAV used for Photogrammetry: a) UAV with integrated sensor and remotely operated device; b) UAV taking photography 
The GPS (Trimble R6) measurements on the basis of station Vilnius of LitPOS network are carried out applying Rapid Static method and have been used for determination of ground control points coordinates exploited in exterior orientation procedures. Fragment of test area and distribution of ground control point is shown in Figure 3.

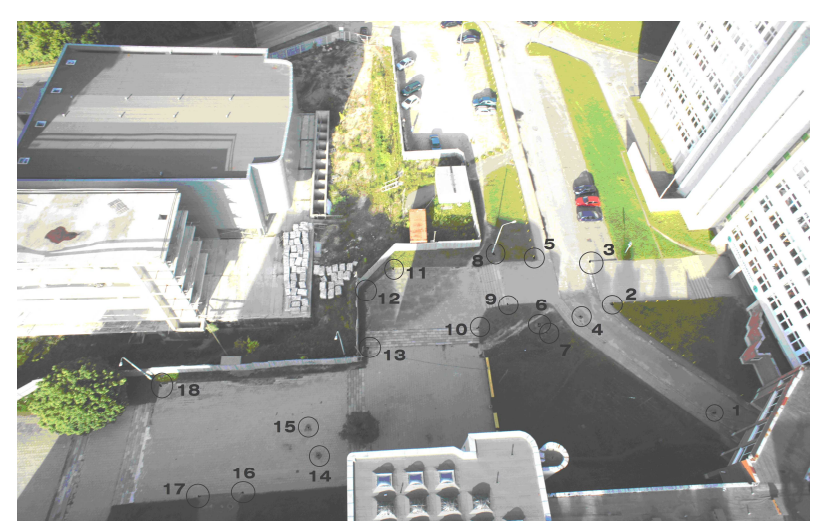

Figure 3. Distribution of ground control points in the test area

\subsection{Generating Geospatial Data Sets: DEMs and Orthoimages}

DTM's creation via image matching and area mapping was performed by software LISA designed at University of Düsseldorf (Linder, 2009; Ruzgiene, 2010). The software's package is divided into modules: BASIC, FOTO, BLUH, FFSAT and can be used for various photogrammetric tasks. Processed stereoscopic pair of images (from UAV platform) is showed in Figure 4. The overlap of photographs is about $85 \%$.
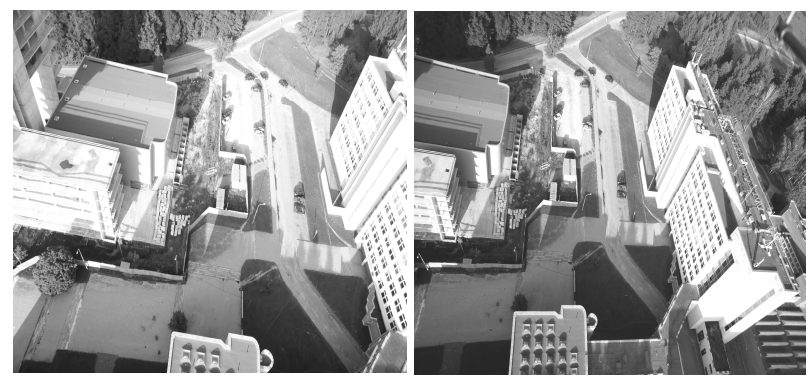

Figure 4. Experimental images - stereo pair

Exterior (absolute) orientation of photographic images was based on 18 reference (ground control) points. The maximum residual error of absolute orientation of the left photograph is $0.381 \mathrm{~mm}$, and standard deviation is $0.180 \mathrm{~mm}$ referring to the image (see Figure 5).

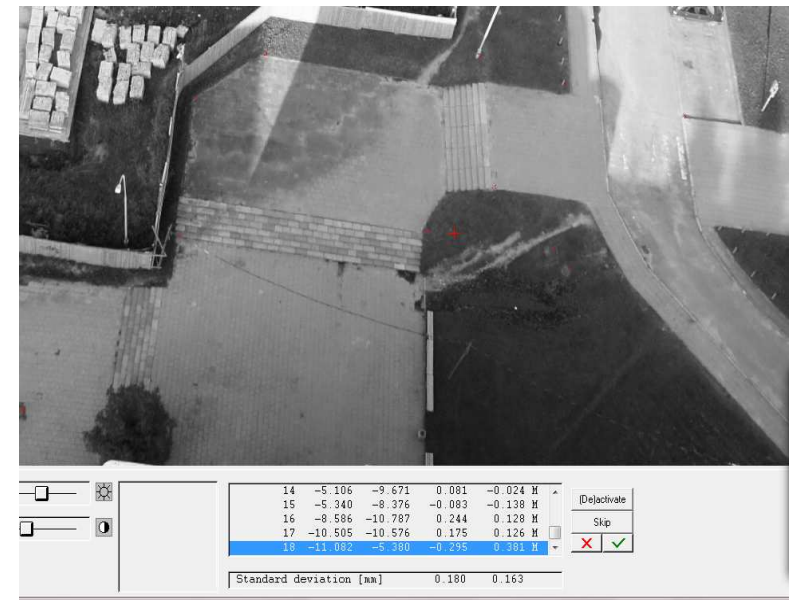

Figure 5. Fragment of results from exterior image orientation - UAV Photogrammetry

The results of the right image exterior orientation accuracy are similar. The significant wind angles of images have been determined.

The maximum residuals in $\mathrm{x}$ and $\mathrm{y}$ at every point and the resulting standard deviation in exterior orientation procedure of images from Close Range Photogrammetry taken photos with digital camera Samsung ES10 respectively are: 0.029 $\mathrm{mm}$ and $0.020 \mathrm{~mm}$ (Figure 6). Residuals are less than half of image pixel size referring to the image.

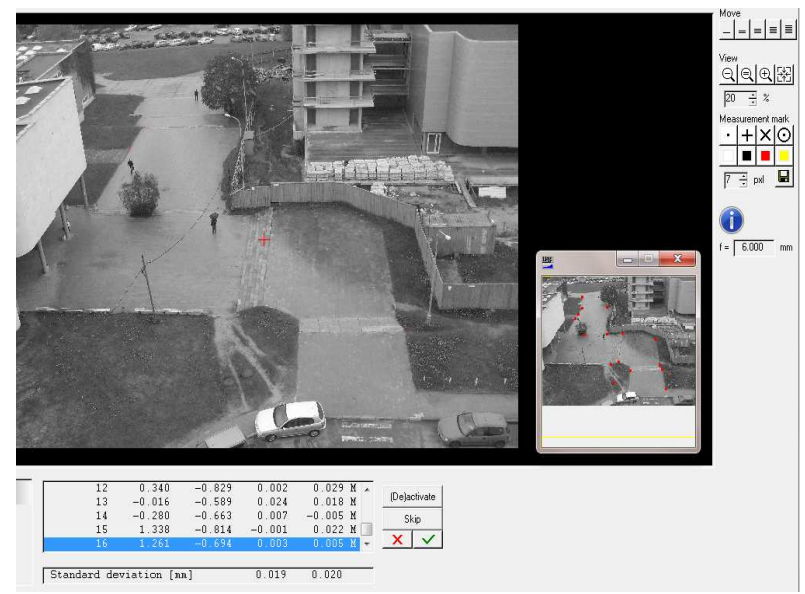

Figure 6. Fragment of results from exterior image orientation - Close Range Photogrammetry

Creation of DTMs via image matching (from about 12000 matched points) and orthophoto generation has been executed using images from both approaches. Figure 7 demonstrates fragment of created orthophoto with representation of relief. 


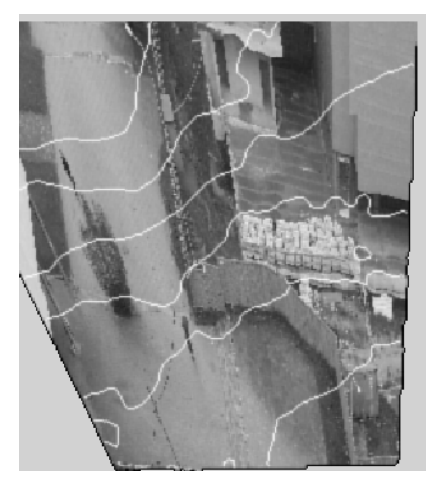

Figure 7. Fragment from orthophotographic rectification results with contours (interval $0.5 \mathrm{~m}$ ) overlaid - Close Range Photogrammetry

\subsection{Analysis of images accuracy from the UAV Photogrammetry and Close-Range approaches}

The image point's position accuracy depends on the camera sensor characteristics, the flight height, positioning of the GPS system, and some other factors.

The horizontal accuracy is closely related with the flight altitude $-1 / 2000-1 / 3000$ of flying height. UAV flying height is about $300 \mathrm{~m}$, therefore, the error is about $0.10-0.15 \mathrm{~m}$.

The main goal was to investigate point accuracy from UAV Photogrammetry image data and Close Range Photogrammetry image taken over test area. For the evaluation of the image data accuracy a comparison with geodetic control measurements has been carried out. A certain amount of image points was coordinated using GPS (Trimble R6) (Figure 8). The ellipsoidal heights of GPS points determined with accuracy - up to $\pm 30 \mathrm{~mm}$. The accuracy of heights transformation to the normal system is $3 \mathrm{~cm}$. The average accuracy of ground control point positioning by the GPS (determination of planimetric coordinates) is about $15 \mathrm{~mm}$.

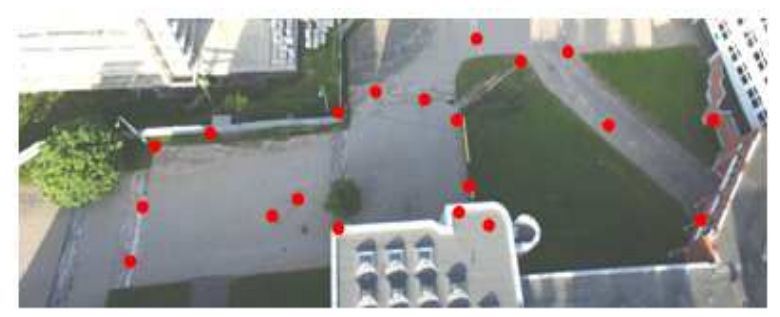

Figure 8. Fragment of points selected for coordinates checking

The search of image points for geodetic control was carried out at a variable distances, e.g. from 1.0 up to $20 \mathrm{~m}$. The distribution of height deviations is presented in Table 1.

\begin{tabular}{|l|c|c|c|c|c|c|c|}
\hline \multirow{2}{*}{$\begin{array}{c}\text { Technology } \\
\text { /number of } \\
\text { points }\end{array}$} & \multicolumn{6}{|c|}{ Deviations number at intervals, $\mathrm{m}$} \\
\cline { 2 - 8 } & 0 & $0.01-0.10$ & \multicolumn{2}{|c|}{$0.11-0.20$} & $0.21-0.30$ \\
\cline { 2 - 8 } & + & - & + & - & + & - \\
\hline UAV & - & 11 & 8 & 21 & 6 & 6 & 2 \\
\hline Close Range & - & 16 & 7 & 22 & 4 & 4 & 1 \\
\hline
\end{tabular}

Table 1. Distribution of point's numbers regarding to defined coordinates deviations

The accuracy of the image height points was investigated comparing UAV image data with geodetic control. Root Mean Square (RMS) and Standard deviation StD $\left(\sigma_{z}\right)$ has been calculated using formulae (1), so reducing influence of systematic errors influence (Žalnierukas, 1999; Ruzgiene, 2011).

$$
\begin{aligned}
& \sigma_{z}=\sqrt{\frac{1}{n}\left(\sum \Delta^{2} Z-n \bar{\Delta}^{2} Z\right),} \\
& (R M S)^{2}=\sigma_{z}^{2}+\bar{\Delta}^{2} Z .
\end{aligned}
$$

where $\quad \Delta Z=Z_{\text {img }}-Z_{\text {geod }}$,

$$
\begin{aligned}
& \bar{\Delta} Z \text { - mean of deviations, } \\
& n \text { - number of checked points. }
\end{aligned}
$$

\begin{tabular}{|c|c|c|c|c|c|c|}
\hline \multirow[b]{2}{*}{ 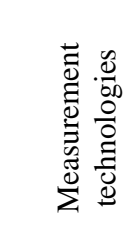 } & \multirow[b]{2}{*}{ 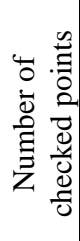 } & \multicolumn{5}{|c|}{ Accuracy assessments, $\mathrm{m}$} \\
\hline & & 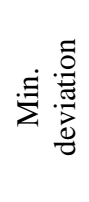 & 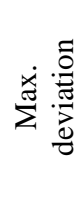 & 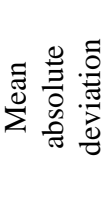 & 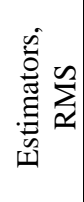 & 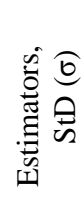 \\
\hline \multicolumn{7}{|c|}{ Accuracy of planimetric coordinates $(x, y)$} \\
\hline UAV & \multirow[b]{2}{*}{54} & -0.05 & 0.30 & 0.18 & 0.20 & 0.25 \\
\hline $\begin{array}{l}\text { Close } \\
\text { Range }\end{array}$ & & -0.04 & 0.20 & 0.15 & 0.14 & 0.15 \\
\hline \multicolumn{7}{|c|}{ Accuracy of point heights } \\
\hline UAV & \multirow[b]{2}{*}{54} & -0.06 & 0.17 & 0.12 & 0.09 & 0.11 \\
\hline $\begin{array}{l}\text { Close } \\
\text { Range }\end{array}$ & & -0.05 & 0.12 & 0.10 & 0.05 & 0.07 \\
\hline
\end{tabular}

Results of UAV image and Close Range image point's coordinates accuracy investigation considering to geodetic measurements by GPS are presented in Table 2 .

Table 2. Results of point coordinates accuracy investigation compared with geodetic control measurements

\section{CONCLUSIONS}

UAV Photogrammetry, getting images from bird fly, and combined with Close Range Photogrammetry data is useful for accurate land surface mapping and fulfils the requirements for the creation of spatial city terrain models.

The UAV Photogrammetry points positioning accuracy in consideration with geodetic control measurements show, that the average RMS for height points is $0.09 \mathrm{~m}$. This proves a 
very high accuracy of point's height measurement using UAV platform for taking images.

The horizontal accuracy is about $0.12 \mathrm{~m}$ when flying height is $300 \mathrm{~m}$. Experimental accuracy investigation regarding UAV Photogrammetry and GPS data shows that maximum absolute planimetric displacement is up to $0.30 \mathrm{~m}$. It can be stated that, under the current accuracy data the UAV data is suitable for creation of 3D models for the urban area and fulfils the accuracy requirements for large-scale topography and GIS needs.

The results from accuracy investigation using Close Range approach has been received similar as from UAV Photogrammetry (c.f. Table 2).

The photogrammetric software LISA is excellent program package represents small, but powerful Digital Photogrammetric Workstation and can be successfully used for photogrammetric tasks. However, some limitation (image size, only grey scale images) reduced functionality of image processing and influenced the results. By using other software for the photogrammetric data analysis can improved and speed up results.

As well as, because of significant oblique UAV images needs the special designed images processing software for digital terrain model creation and orthophoto production with desirable $5-10 \mathrm{~cm}$ resolution.

\section{References}

\section{References from Journals:}

Ruzgienè, B., 2010. Skaitmeninio reljefo modelio kūrimo metodai ir tikslumo tyrimas, taikant skaitmeninès fotogrametrijos technologija [Methods of digital relief model creation and accuracy investigation, applying digital photogrammetry technology]. Geodezija ir kartografija [Geodesy and Cartography], 36 (2), pp. 57-62.

Žalnierukas, A.; Kumetaitienè, A., 1999. Topografiniu duomenų bazių, sukurtu stereofotogrametriniu būdu, tašku altitudžiu tikslumas. [Accuracy of point elevations of topographical database created by stereophotogrammetric approach]. Geodezija ir kartografija [Geodesy and Cartography], XXV (3), pp 113-118.

\section{References from Books:}

Eisenbeiss, H., 2009. UAV photogrammetry. ETH Zurich, Switzerland, Mitteilungen, p. 235.

Linder, W., 2009. Digital Photogrammetry. A practical Course. Springer-Verlag, Berlin, Heidelberg, pp. 33-73, 121131.

Luhmann, T.; Robson, S.; Kyle, S; Harley, I., 2006. Close Range Photogrametry. Principles, Methods and Applications. Scotland, Dunbeath: Whittles Publishing, pp 319-397.

Manual of Photogrammetry (Edited by J. Chris McGlone), 2004. American Society for Photogrammetry and Remote Sensing, Maryland, USA, pp. 959-963.

Ruzgienè, B., 2008. Fotogrametrija. Vilnius: Technika, pp 93-132.

\section{References from Other Literature:}

Ruzgiene, B.; Žalnierukas, A., 2011. Creation of an urban spatial model using laser-scanning. In: The $8^{\text {th }}$ International Conference "Environmental Engineering", Volume III, VGTU Press „Technika“ scientific book No 1867-M, pp. 1455-1458.

\section{References from websites:}

Khosravani A. M., 2010. Digital Preservation of the Hirsau Abbey by Means of HDS and Low Cost Close Range Photogrammetry.

http://www.geoengine.uni-stuttgart.de/forum/master/ali-

khosravani/index.html. (21 Jan 2013).

Nilsson, H. F.; Grundberg, D., 2009. Plane-Based Close Range Photogrammetric Reconstruction of Buildings. Umea University, Sweden.

http://www8.cs.umu.se/research/uminf/reports/2009/018/part1 .pdf (20 Jan 2013).

UAV Systems-Unmanned Aerial Photography. AUVSI. http://www.uavsystems.com.au/ (22 March 2013).

\section{Acknowledgment}

The co-operation with Egle Tamašauskaite from master student at Geodesy and Cadastre Department and Evaldas Črniauskas from Aviation Institute, VGTU is highly appreciated. 